\title{
LIVRO DE ARTISTA: ENSINO E POÉTICA NO CURSO DE DANÇA
}

\author{
Mariana Lopes Junqueira 1 \\ Mestranda em Educação \\ marianalopesjunqueira@gmail.com.br \\ Carla Carvalho ${ }^{2}$ \\ Doutora em Educação \\ ca_carvalho@icloud.com
}

\section{INTRODUÇÃO}

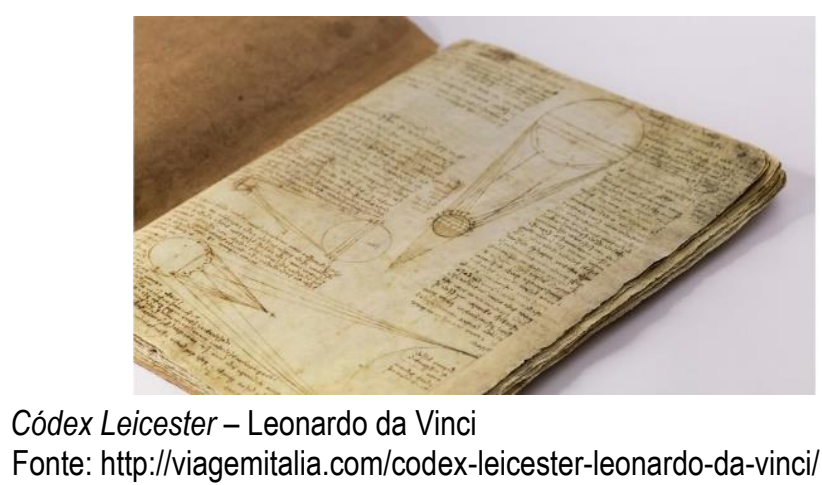

Como podemos observar na epígrafe deste estudo, o Códex Leicester, manuscrito com os estudos de Leonardo da Vinci, além de conter suas anotações, trazia desenhos. Esses manuscritos de Leonardo da Vinci, além de livros, são verdadeiras obras de arte. Nesse lugar que discute o limite ou os não limites da arte é que se insere este estudo ou o registro deste estudo. Olhamos, hoje, para o livro de Leonardo e nos questionamos se este pode ser considerado um objeto artístico. Podemos afirmar que, em sua época, no alto da Renascença, ele era considerado apenas um livro de registro do artista, arquiteto, engenheiro e grande inventor que era Da Vinci.

Olhando para esse lugar da arte em nosso tempo, seus limites ou não limites, interessa-nos pensar as suas possibilidades no campo da educação e desta como arte, como potência de sensibilidades e saberes. Este estudo está vinculado ao grupo de pesquisa Arte e Estética na Educação, da Universidade Regional de Blumenau (FURB). O grupo de pesquisa tem se voltado a discussões em torno da integração do fazer artístico às pesquisas e trabalhos acadêmicos em educação, para que a

\footnotetext{
${ }^{1}$ Mestranda em Educação pela FURB. Atua como professora de Arte com ênfase em Educação Musical.

${ }^{2}$ Doutora em Educação pela Universidade Federal do Paraná (2008). Atua como professora no Programa de Pós-Graduação em Educação e na graduação na FURB.
}

Revista "O Teatro Transcende" Departamento de Artes - CCEAL da FURB - ISSN 2236-6644 - Blumenau, Vol. 23, № 1, p. 81 - 91, 2018 - Edição Especial dos 45 Anos de Artes na FURB. 
arte não seja apenas tema de estudo, mas que a arte possa estar inserida nele. Este estudo é de abordagem qualitativa e tem como objetivo discutir a poética no ensino por meio do livro de artista.

Livro, segundo o dicionário, é um conjunto de folhas de papel em branco, escritas ou impressas, em brochura ou encadernadas; obra organizada em páginas, manuscrita, impressa ou digital; o que serve de instrução (PRIBERAM, 2018). Quando o artista se envolve na construção do livro como obra de arte, o livro é considerado um livro de artista, que também pode ser chamado de livro-objeto, livro ilustrado, livro de arte, livro poema, poema-livro, livro-arte, arte-livro, livro-obra (SILVEIRA, 2001). A partir dos anos 1960, com o livro de Marcel Duchamp, intitulado A Caixa (1914), é que se intensificou a produção dos livros de artista.

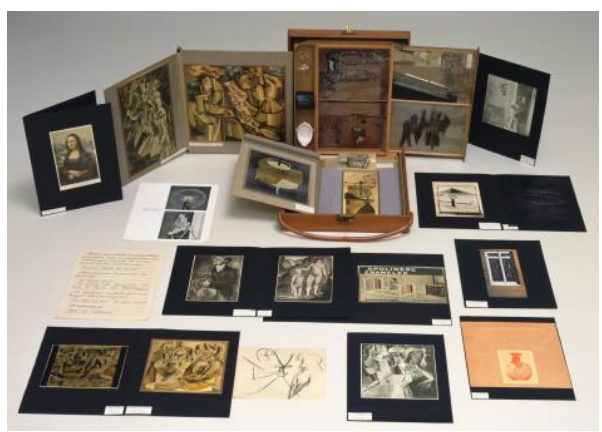

Fig 1 - A Caixa

Fonte: http://iradex.net/14243/semiotica-de-building-stories-hq-sem-roteiro-podcast/caixa-valise-marcel-duchamp/

O livro de artista lida com o livro de uma maneira artística e poética, ou seja, vai para além de guardar apenas conteúdo. O que aproxima o livro de artista de todos os outros gêneros de livros que existem é, em um primeiro instante, a semelhança à forma do livro, e o que os diferencia é que os livros cumprem o seu destino de serem funcionais, ou seja, os livros abrigam conteúdos independentemente de seu suporte(DERDYK, 2013). Conforme Derdyk (2013):

\begin{abstract}
No livro "funcional", o suporte é um contêiner isento, ausente de si mesmo, cuja forma e materialidade estão ali para agarrar, fixar e preservar memórias ou estender, alongar e projetar imaginários, diferentemente do livro de artista cujo suporte é, essencialmente, um espaço poético do "aqui do onde" e do "agora do quando". Isso quer dizer que no livro de artista o "suporte" é a temporalidade que se atualiza a cada instante em que o livro é lido, visto, tocado, manuseado. E assim o tal "suporte" deixa de suportar depósitos gráficos para ser uma superficie extensiva, folhas "quase cinema", um campo de aterrisagem para sinais transitivos, com alta voltagem poética. (DERDYK, 2013, p. 12, grifos do autor)
\end{abstract}

No livro de artista não sabemos ao certo o que iremos encontrar, diferente de um livro funcional cujo conteúdo já conhecemos previamente. No livro de artista, a narrativa pode acontecer por meio de 
conexões inusitadas entre palavra e imagem, como por ações materiais e físicas exercidas sobre a superfície das folhas, fazendo com que o leitor manuseie de forma inédita o livro. Nesse sentido, o próprio livro de artista se considerado como pré-texto poético, ou seja, todas as suas partes construtivas do livro, forma e conteúdo, significante e significado tornam-se inseparáveis e indissociáveis (DERDYK, 2013). Dessa forma, cada livro de artista pode ser "tão específico e abrangente, capaz de abraçar todos os livros do mundo e não ser nenhum deles ao mesmo tempo, cada livro de artista será o motor que anima e movimenta a geração infinda de pensamentos e teorias e conceitos a respeito desse modo de produzir arte" (DERDYK, 2013, p. 13,14).

O livro de artista não precisa conter especificamente a forma de um livro, pois, conforme Silveira (2001), pode ser referente a ele, com questões de afeto expressadas através de propostas gráfica, plásticas ou de leitura. O livro de artista, também abarca o tempo, segundo Silveira (2001),

O primeiro grande elemento ordinal no livro é a sequencialidade na percepção ou na leitura. Ela é a diretriz da ordem interna da obra, envolvendo a interação mecânica do leitor ou fruidor. Um livro envolve o tempo de sua construção e os tempos de seu desfrute. Cada vez que viramos uma página, temos um lapso e o início de uma nova onda impressiva. Essa nova impressão (e intelecção) conta com a memória das impressões passadas e com a expectativa das impressões futuras. (SILVEIRA, 2001, p. 72).

Assim, o livro de artista cria uma relação entre seu leitor/fruidor ao ser manuseado, podendo nos remeter ao tempo passado, assim como nos dar uma expectativa do que está por vir.

\section{LIVRO DE ARTISTA: RELAÇÕES ENTRE ENSINO E POÉTICA}

O livro de artista é resultado específico das artes visuais (SILVEIRA, 2001), mas pode também adentrar outras áreas, como é o caso deste estudo, no qual o livro de artista foi utilizado na área da dança. O livro de artista foi utilizado como uma proposta de atividade para o primeiro semestre do Curso de licenciatura em Dança da Universidade Regional de Blumenau (FURB) em 2017, na disciplina de Arte na Educação. No Projeto Pedagógico do Curso (FURB, 2017, p. 11), a formação didático-pedagógica está dividida em quatro campos: "disposição poética; formação estética/estésica e ética, formação teórica e competências técnicas". Apesar de a disciplina Arte na Educação estar incluída no campo da "Formação Teórica", podemos observar que ela perpassa pelos outros campos, como está contemplado no PPC:

estes campos se articulam ao núcleo e entre si, num movimento dinâmico, pois se observa que nestes componentes curriculares elementos podem ser discutidos nestes ou naqueles 
campos, característica própria da arte e do conhecimento artístico. Assim, nesta matriz, buscou-se olhar para o campo da dança e suas relações com a docência, o conhecimento teórico, prático, poético, estético, estético e ético como campos, linhas que se relacionam dialeticamente (FURB, 2017, p. 36).

Assim, utilizar o livro de artista na aula de Arte na Educação envolve os diferentes componentes curriculares contemplados no PPC, de forma dinâmica e hibrida. De modo que, como o próprio PPC aborda, tanto o artista como o professor de arte, em seu percurso de formação, são compreendidos como a razão indissociável da emoção ou sensibilidade (FURB, 2017). O livro de artista também perpassa pela poética, pois, conforme Derdyk (2013):

As possibilidades conceituais/formais, que se entreabrem a partir da investigação do livro como objeto poético, desenham um arco extenso de experimentações, congregando 0 conhecimento artesanal aos processos industriais, potencializando a mixagem de várias linguagens e modalidades de registros visuais e literários, multiplicando a descoberta de estruturas narrativas dadas pelos entrelaçamentos inusitados entre a palavra e a imagem. 0 livro de artista nos convida para caminhar nessa paisagem feita de campos de cultivo híbridos, sugerindo o convívio das diferenças. (DERDYK, 2013, p. 12, grifos do autor).

Nas primeiras aulas, foram trabalhos vários exemplos de livros de artista como do Leonardo da Vinci, Marcel Duchamp, Monica Barbosa, Waltércio Caldas, Antonio Alves, Artur Barrio, entre outros.

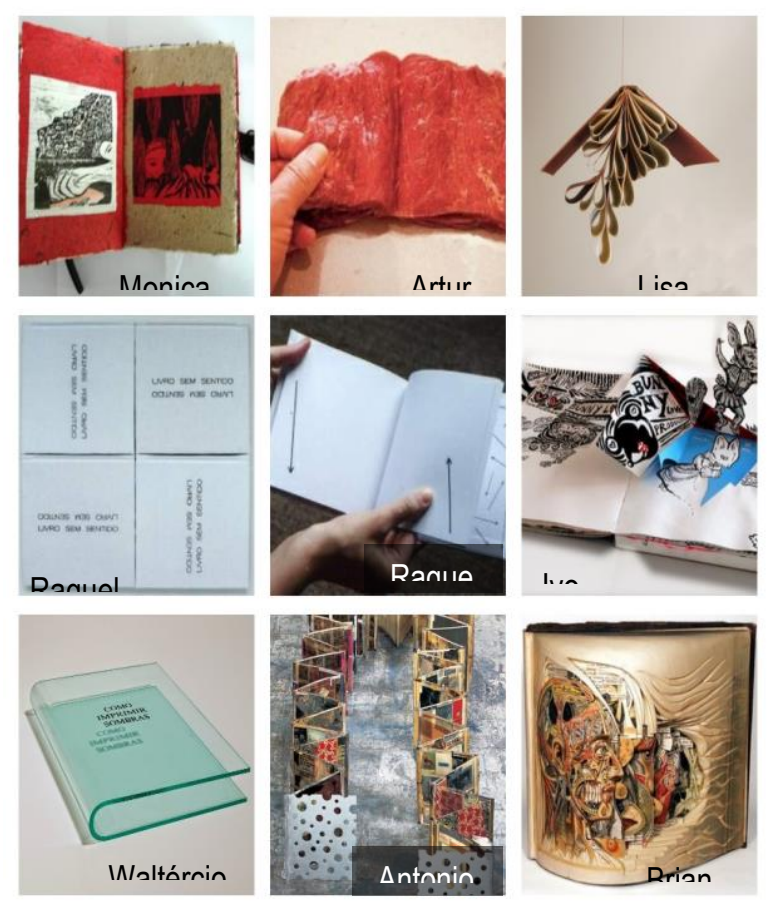

Fig. 2 - Livros de artista 
Fonte: Colagem criada pelas autoras ${ }^{3}, 2018$.

Diante dos exemplos trabalhados, o livro de artista que os estudantes iriam criar deveria: relacionar o tema da disciplina Arte na Educação com a história de cada acadêmico, ser criativo e deixar pistas sobre os temas discutidos em cada aula. A disciplina tinha como ementa a inserção da arte na educação e seu contexto histórico no Brasil; tendências pedagógicas do ensino da arte; e teóricos da arte na educação. Os alunos tiveram o decorrer do semestre para produzir seus livros de artista. No último dia de aula, os alunos trouxeram seus livros de artistas para que os colegas pudessem apreciar e, depois, cada estudante pôde comentar sobre o seu livro.

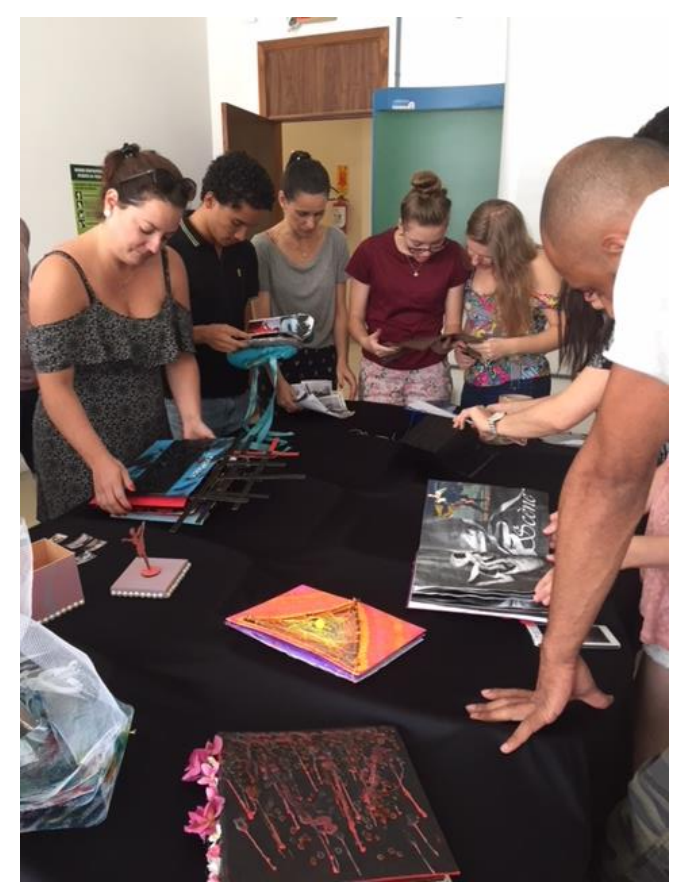

Fig. 3 - Momento de apreciação dos livros de artista Fonte: acervo das autoras, 2018.

Conforme Neves (2013), os livros de artista podem abarcar componentes formais, culturais, gestuais, gráficos, simbólicos, comunicacionais e registros sensíveis apresentados como possibilidades a serem experimentados artisticamente no processo criativo. Nesse sentido, os livros de artista possuem

\footnotetext{
${ }^{3}$ Disponível em (seguindo a ordem das imagens): http://livrodeartista.blogspot.com/2006/03/projeto-alfarrbios-livro-deartista.html; http://www.ideafixa.com/oldbutgold/originalidade-x-reinterpretacao; http://portaldoprofessor.mec.gov.br/fichaTecnicaAula.html?aula=26439; http://muvi.advant.com.br/artistas/r/raquel_stolf/ivro_sem_sentido.htm; http://diario-grafico.blogspot.com/2006/12/livro-deartista-1.html; http://gramatologia.blogspot.com/2014/04/waltercio-caldas.html; https://antonioalves.blogs.sapo.pt/livros-deartistas-livros-concertina-1851.
} 
"informações apreendidas e codificadas, num diálogo íntimo entre o artista, que é uma espécie de receptáculo de emoções e visualidades, e seus desejos e escolhas sobre o mundo, numa tentativa de comunicar e de conferir consistência à obra" (NEVES, 2013, p. 65). Percebemos, portanto, que as materialidades foram das mais diversas e dialogaram com as subjetividades de cada integrante do grupo.

$\mathrm{Na}$ análise dos livros, podemos observar aspectos que se relacionam com suas vidas, com os contextos que percorreram como estudantes e artistas, com o componente curricular abordado e temáticas presentes em nosso tempo. Os livros de artistas trouxeram aspectos que relacionam a dança na vida, na escola e no contexto profissional dos acadêmicos.

Pelos livros, identificamos que as experiências que os estudantes tiveram em dança, na grande maioria, foram extracurriculares, quando se referiam aos espaços escolares por eles vividos. Assim, constatamos o que já havia sido discutido em aula que, historicamente, a Dança não está presente nas escolas.
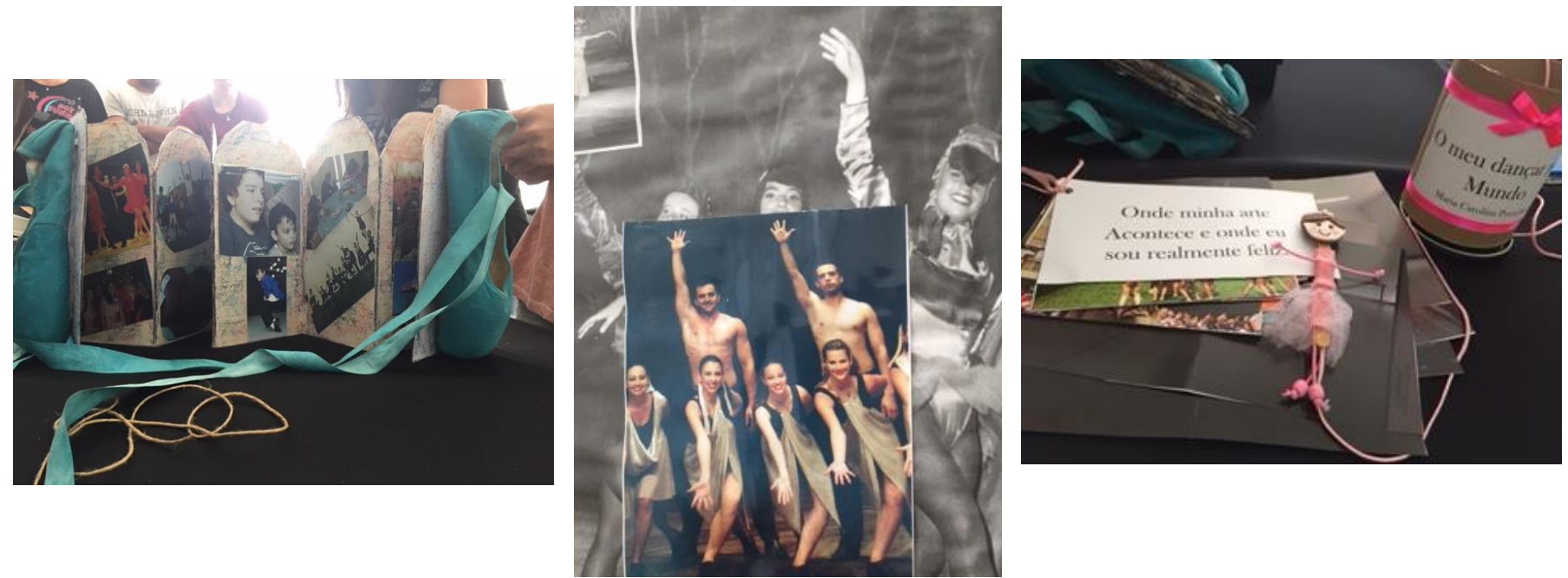

Fig. 4, 5 e 6 - Livros de artista dos estudantes Fonte: acervo das autoras, 2018.

Nos livros de artista, os elementos teóricos trabalhados durante a disciplina transversalizaram as produções artísticas. Assim, notamos o quanto a discussão sobre a Arte na Educação e a forma como ela acontece marcaram cada estudante. Observamos que as relações não foram realizadas como num portfólio, por exemplo, no qual se coloca o que discutimos em cada aula, mas sim integrado ao contexto do que relataram integrado ao que compreenderam das aulas num todo. 

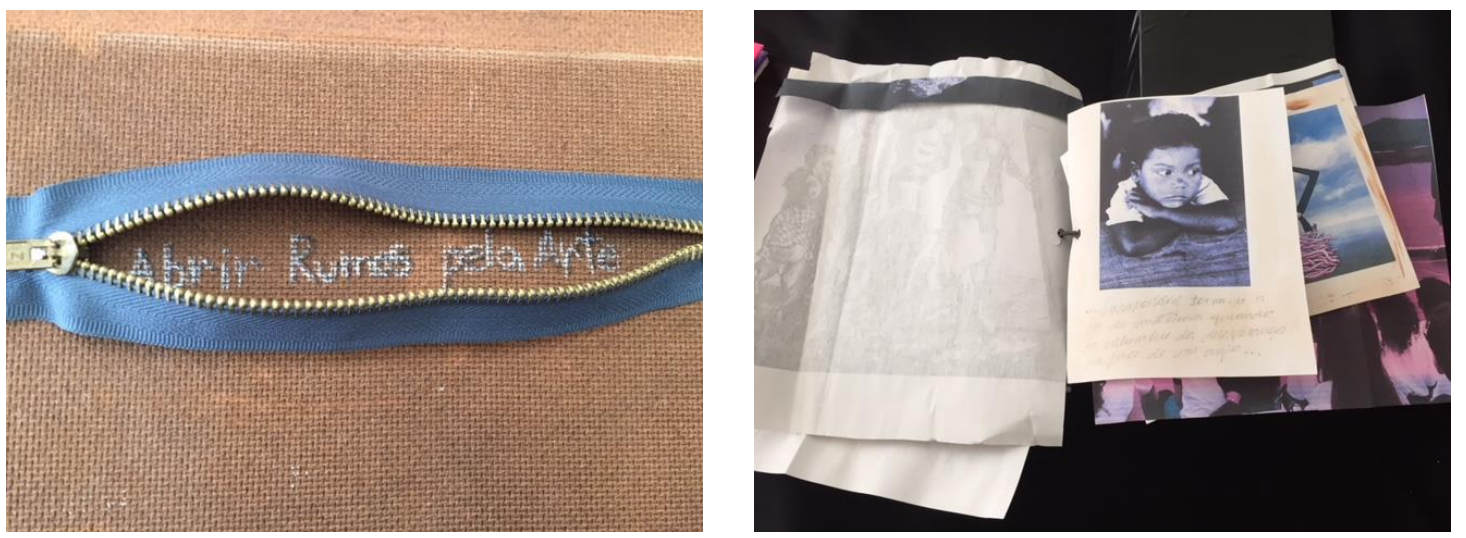

Fig. 7 e 8 - Livros de artista dos estudantes Fonte: acervo das autoras, 2018.

Para além dos elementos teóricos, em relação aos aspectos formais dos livros de artista, os estudantes utilizaram signos da dança na forma do livro para dar volume à visualidade. Nesse sentido, nem todos os estudantes ficaram presos à forma do livro tradicional. Esse aspecto é muito interessante e rico, considerando que nenhum estudante desse grupo tem inserção no campo da visualidade como estudo específico. Ainda assim, trouxeram aspectos como o uso das sapatilhas, o uso do Tutu, uma caixa como se fosse uma caixa de música com bailarina, para atribuir tridimensionalidade ao livro. Recurso muito importante e, ao mesmo tempo, relacionado aos seus contextos pessoais.
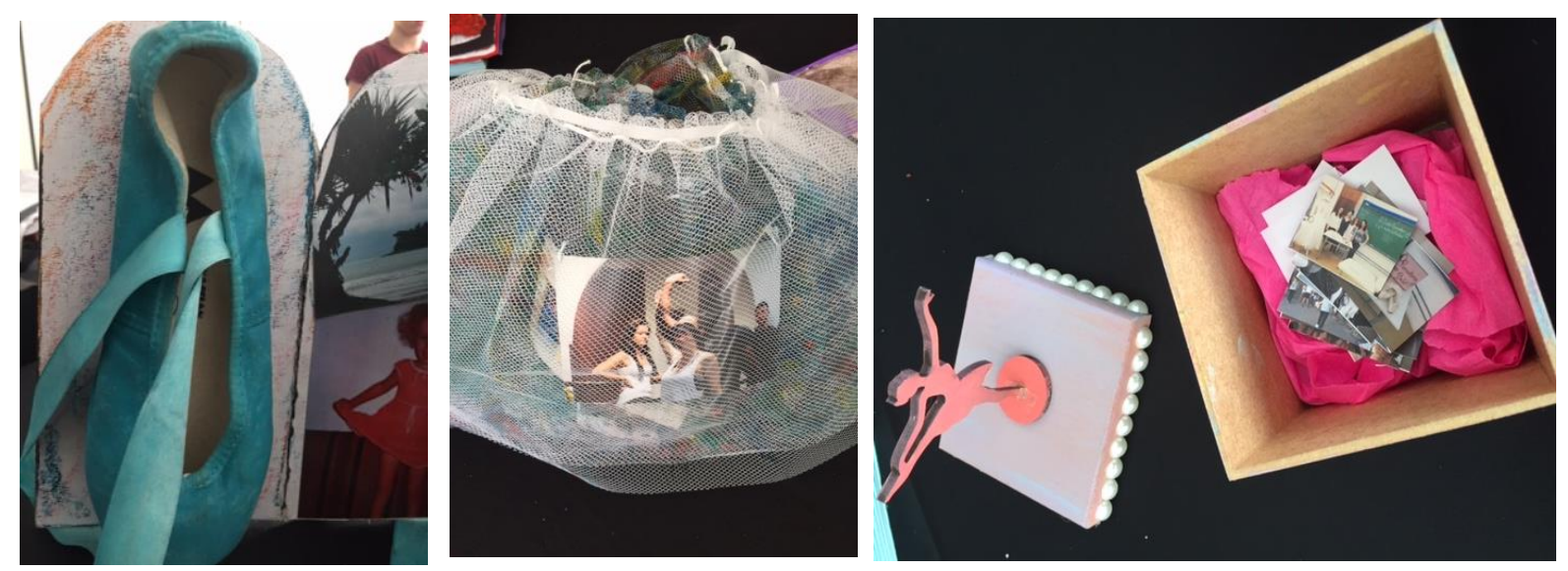

Fig. 9, 10 e 11 - Livros de artista dos estudantes

Fonte: acervo das autoras, 2018. 


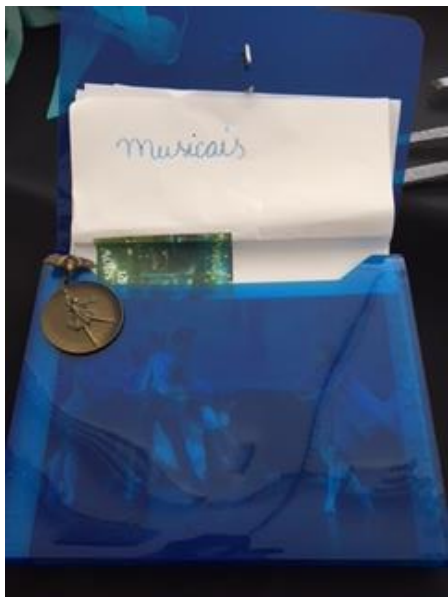

Fig. 12 - Livro de artista de uma estudante Fonte: acervo das autoras, 2018.

A figura 12 lida com questões de colecionismos, com páginas nas quais a autora registra percursos que a faz sentir-se empoderada na medida em que começou a dançar. Esse registro demonstra sua relação e seu longo percurso com a dança, presente em outros livros de artista, mas aqui, enquanto estrutura de livro opta por contar uma história linear desse processo.
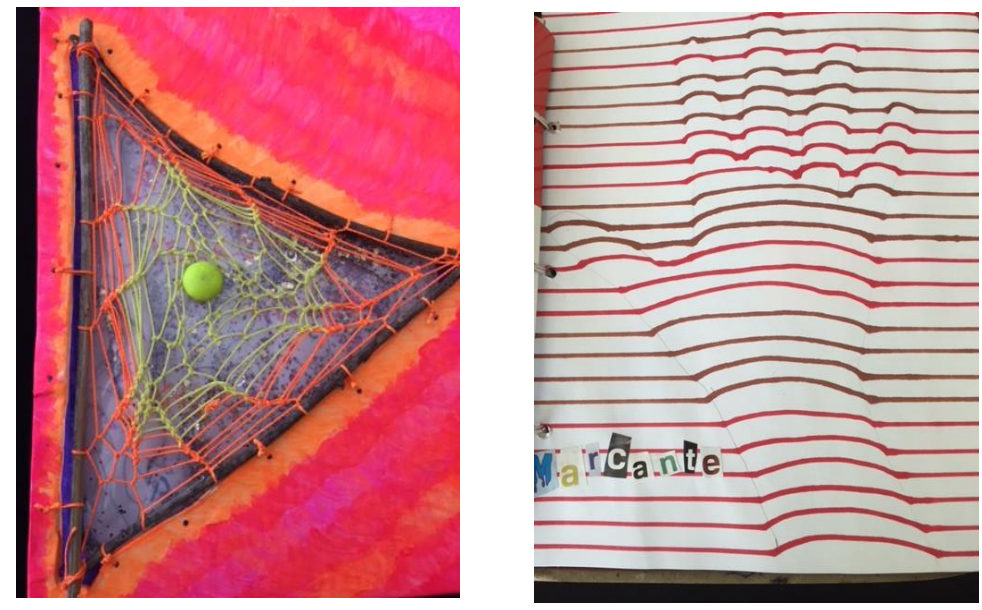

Fig. 13 e 14 - Livro de artista de uma estudante Fonte: acervo das autoras, 2018.

As figuras 13 e 14 demonstram um processo bastante interessante de relação entre forma e conteúdo. Suas imagens levam a conceitos, a uma relação íntima com a visualidade, indicando relação entre tramas de vida, poder e marcas que a dança deixa em sua vida. Esse processo é bastante interessante e demonstra, acena o uso cuidadoso dos recursos visuais. 
Um dos livros lidou especialmente com questões de sexualidade e gênero. Essas questões também emergiram e foram discutidas durante as aulas, por exemplo quando discutimos sobre como era a aula de artes dos estudantes quando estavam no Ensino Fundamental, foi relembrado o preconceito dos colegas de sala pela escolha dos meninos pela dança. Outro acontecimento, que também foi discutido durante a aula, foi o cancelamento da exposição Queermuseu - cartografias da diferença na arte brasileira, pelo Santander Cultural, em 2017 e a preocupação da censura à arte. Nesse sentido, vemos a importância de se discutir, em sala, questões que acontecem ao nosso redor, não ficando presos apenas ao planejamento da disciplina.
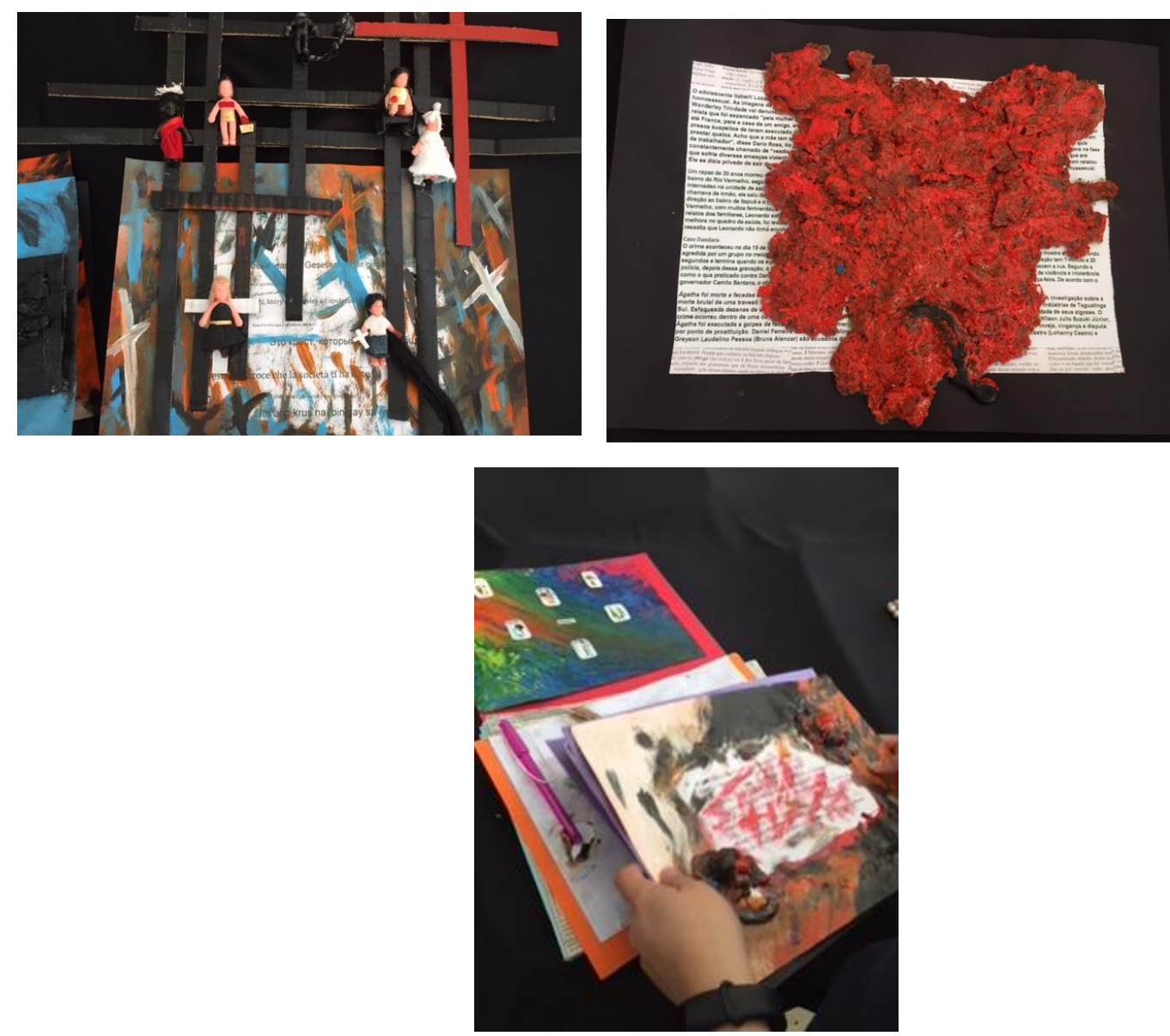

Fig. 15, 16 e 17 - Livro de artista de um estudante Fonte: acervo das autoras, 2018.

Um dos estudantes optou por registrar seu livro em um pedaço de couro, apesar de sua efemeridade, pois a tinta da caneta ia se apagando com o passar do tempo, quis registrar justamente a marca da dança e das discussões sobre a arte na educação que ficaram marcadas em sua pele. 0 que 
demonstra que, para o estudante, suas relações com a dança e educação foram uma experiência marcante, conforme Larrosa (2017, p. 25), "o sujeito da experiência seria algo como um território de passagem, algo como uma superfície sensível que aquilo que acontece afeta de algum modo, produz alguns afetos, inscreve algumas marcas, deixa alguns vestígios, alguns efeitos".
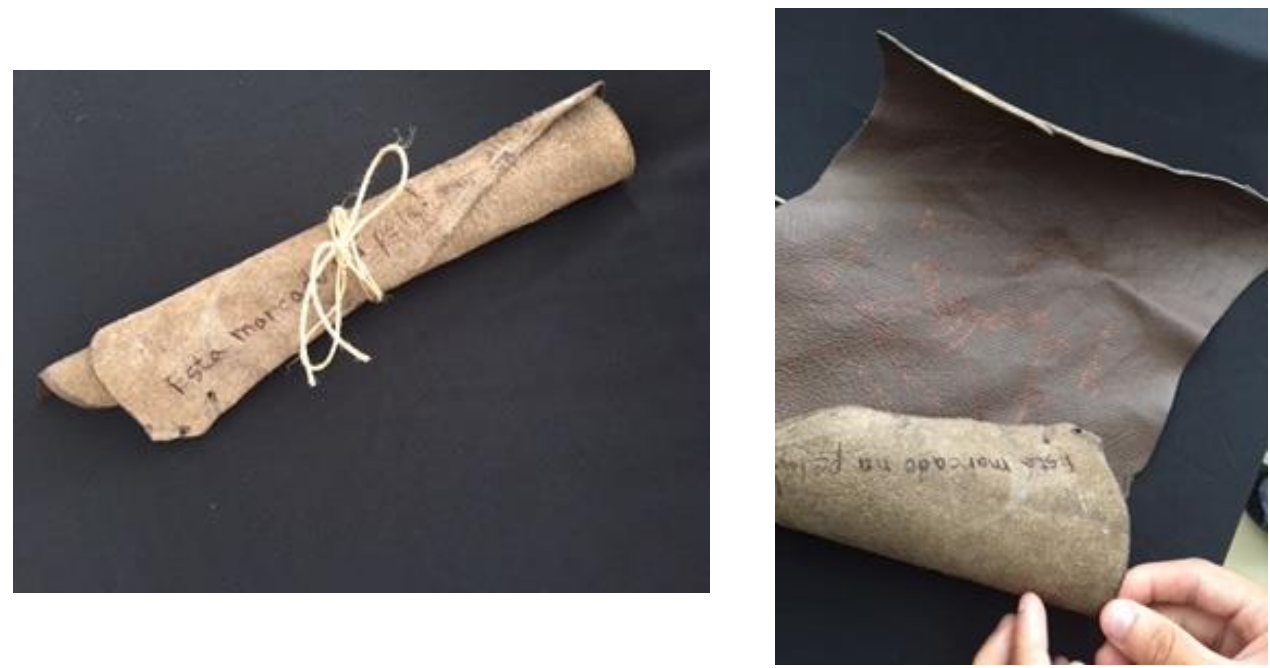

Fonte: acervo das autoras, 2018.

Teve um livro, que lidou com relações entre linguagens com movimento. Além do registro em fotografias, o estudante apresentou seu livro por meio da dança, demonstrando que a arte permeia as questões do ensino e docência de forma híbrida. Dessa forma, o estudante trouxe o movimento e o corpo para o ensino, a partir disso, podemos compreender que são questões que não podem estar apartadas de um curso que lida com isso.

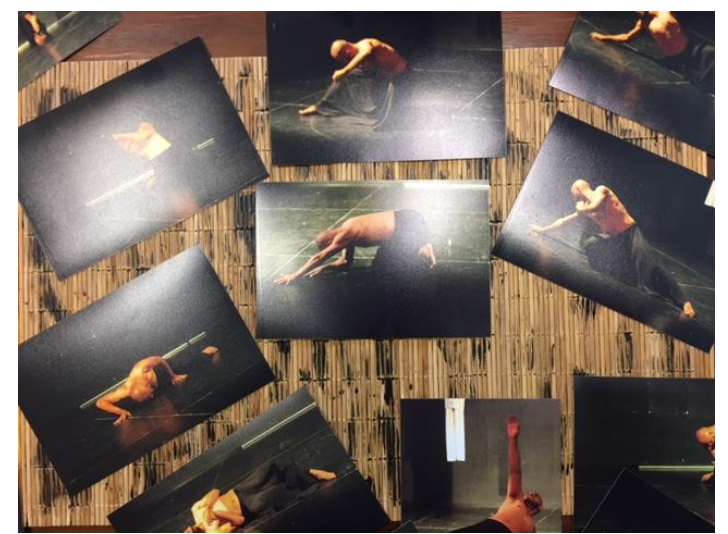

Fig. 20 - Livro de artista de um estudante

Fonte: acervo das autoras, 2018. 


\section{ALGUMAS CONSIDERAÇÕES}

O livro de artista foi uma atividade que permitiu aos estudantes lidarem com a arte e a poética de maneira integrada com questões teóricas. Nos livros de artista dos estudantes, identificamos os elementos teóricos trabalhados na disciplina, assim como episódios referentes à arte que ocorreram em nosso país e que foram discutidos nas aulas, pois a disciplina não pode se prender apenas ao seu planejamento, ficando alheia ao que acontece fora da universidade.

Percebemos, ainda, o livro de artista como uma possibilidade de poetizar, de fazer arte, de descobrir outras possibilidades com as linguagens. Por meio do livro, conhecemos os estudantes, percebemos suas subjetividades e aspectos que nos aproximam no sentido de coletividade. Relacionamos teoria e prática no sentido de práxis, compreendendo que uma não existe sem a outra numa relação dialética e dinâmica.

Por meio dessa atividade, observamos que o Ensino Superior pode se voltar para modos contemporâneos de ensino, principalmente quando o curso lida com questões de arte e criatividade. Identificamos um movimento no curso de Dança, que rompe com o ensino tradicional, visando à criatividade, estética e à poética para além do ensino teórico em um ensino entre linguagens.

\section{REFERÊNCIAS}

DERDYK, Edith. Entre ser um e ser mil. In: DERDYK, Edith (Org.). Entre ser um e ser mil: o objeto livro e suas poéticas. São Paulo: Senac São Paulo, 2013. Cap. 1. p. 9-15.

FURB. Projeto Político do Curso de Dança - Licenciatura. Blumenau, 2017.

LARROSA, Jorge. Tremores: escritos sobre experiência. Belo Horizonte: Autêntica, 2017.

NEVES, Galciani. Entre páginas e não páginas: breve inventário de livros de artistas. In: DERDYK, Edith (Org.). Entre ser um e ser mil: o objeto livro e suas poéticas. São Paulo: Senac São Paulo, 2013. Cap. 4. p. 61-91.

SILVEIRA, Paulo. A página violada: da ternura à injúria na construção do livro de artista. Porto Alegre: UFRGS, 2001. 